\title{
AL-AZHAR
}

The Official Publication of The

Assiut Dental Journal

Faculty of Dental medicine,

Al-Azhar Assiut Uniuersity.

Equpt

AADJ, Vol. 3, No. 2, October (2020) - PP. 163:172

ISSn 2682-2822

\section{Efficacy of Bulk Fill Flowable Composite Reinforced with Short Fibers in Fracture Resistance of Restored Extensive Premolars Cavities}

\author{
Ahmed A. Goda ${ }^{* 1}$ and Ahmed D. Abogabal ${ }^{* 2}$
}

Codex : 20/2020/10

Aadj@azhar.edu.eg

\section{KEYWORDS}

MOD restorations,

Bulk fill Flowable composite, Short

fibers, Dentine,

Fracture resistance.

1. Department of Operative Den- tistry, Faculty of Dental Medi- cine (Boys), Assiut, Al-Azhar University, Egypt.

* Corresponding Author e-mail: ahmed.goda.82@azhar.edu.eg

2. Department of Dental Biomaterials, Faculty of Dental Medicine (Boys), Assiut, Al-Azhar University, Egypt.

* Corresponding Author e-mail: ahmeddahy.4419@azhar.edu.eg

\begin{abstract}
Objectives: Tooth fracture is a common complication following MOD restorations. This study sought to assess the effect of bulk fill flowable composite reinforced with short fibers on fracture resistance of maxillary premolar teeth that have extensively restored MOD cavities. Materials and Methods: In this invitro experimental study, 60 human maxillary sound premolar teeth were chosen and stored in chloramine solution. The teeth were then mounted into acrylic blocks $1 \mathrm{~mm}$ below the CEJ. The teeth were randomly divided into 4 groups of 15 each. Group A, Teeth were intact without any cavity (negative control). Wide MOD cavities were prepared using cylindrical bur with high-speed handpiece for the 3 other groups. Group B, the teeth with MOD cavities without any restoration (positive control); Group C, the teeth were restored with bulkfill flowable composite Tetric $\mathrm{N}$ flow bulk fill (Ivoclar Vivadent); and group $\mathrm{D}$, the teeth were restored with short fibers reinforced bulkfill flowable composite ever X Flow(GC). The teeth were then stored in water at $37^{\circ} \mathrm{C}$ for $24 \mathrm{~h}$ and their fracture resistance was assessed using (INSTRON). The load at fracture was recorded in N, fracture mode was observed. Data were analyzed using one-way ANOVA and Tukey's test with 95\% CI. Results: The mean fracture strength was $1216 \pm 352 \mathrm{~N}$ in group $\mathrm{A}, 330 \pm 201 \mathrm{~N}$ in group B, $1013 \pm 389 \mathrm{~N}$ in group C and $1019 \pm 164 \mathrm{~N}$ in group D. Conclusion: Extensive MOD cavities restored with bulk fill flowable composite having short fiber reinforcement, increased the fracture strength of teeth against compressive forces, with no difference than did the other bulk fill flowable composite.
\end{abstract}

\section{INTRODUCTION}

Removal of tooth structure during cavity preparation, especially marginal ridges decreases fracture resistance. Adhesive materials are capable of reinforcing the weakened teeth, resulting in partial or total recovery of fracture resistance. This, in addition to sufficient esthetics and mechanical performance of composite restorations, has led to their routine use in daily practice. ${ }^{(1)}$

Large direct restorations present several challenges especially in the posterior dentition. Mastering of shape, contours, occlusal anatomy and function requires particular skills. One must be aware of the 
potential risk factors and characteristic types of failure in the posterior region. Two main causes of posterior restoration failure have been identified: bulk fracture and secondary caries. Early failure was more closely related to fractures, while caries was more likely to be the background of long-term failure. In long-term studies (with more than 10 years of follow up) that failure was more frequently the result of fracture than of caries. This finding suggests that bulk fracture is a considerable risk to posterior restorations, regardless of the lifespan or the age of these restorations. ${ }^{(2)}$

Layering protocols have been explained by a number of studies showing that layering does not necessarily decrease shrinkage stresses but might even make them worse compared to bulk filling. Hence, In the recent years, manufacturers have shifted their attention toward simplification using new materials for bulk filling, with encouraging results (stress reduction \& strength) in both flowable and packable form. ${ }^{(3)}$

Throughout its well-documented history in industry, the application of fiber-reinforced composite (FRC) technology is constantly evolving as a result of innovative treatment solutions to increase the fracture resistance. Utilizing different types of fibers with various orientations and lengths is quite an old idea in engineering and in architectural applications to construct devices with high strength and fracture resistance. The use of FRC in dental applications has been discussed in the literature since the early 1960s. Today, fiber reinforcement has become an effective material of choice within restorative dentistry. ${ }^{(4,5)}$

In 2013, short fiber- reinforced composite (SFRC) was introduced to the market with the goal to mimic the stress absorbing properties of dentine. The SFRC material is intended to be used as bulk base in high stress-bearing areas for restoring vital and non vital teeth. ${ }^{(6)}$ It presents a higher fracture resistance and flexural modulus within the family of bulk-fill materials but can be used easily in 4-mm deep increments and can potentially match the fracture resistance of dentin. ${ }^{(7,8)}$

It consists of a combination of a resin matrix, randomly-orientated E-glass fibers, and inorganic particulate fillers. The resin matrix contains semiinterpenetrating polymer network (semi- IPN), which provides enhanced bonding properties for repairs and improves the fracture resistance of the polymer matrix. ${ }^{(9)}$

The rationale behind the usage of fiber reinforcement is partly to internally strengthen the structurally compromised tooth and partly to prevent the occurrence of fractures. The efficacy of fiber reinforcement is dependent on several factors; including the resins used, the length of the fibers, the orientation of fibers, the position of the fibers, the adhesion of the fibers to the polymer matrix and the impregnation of the fibers into the resin. ${ }^{(4)}$

The reinforcing effect of the fiber fillers is based on stress transfer from the polymer matrix to the fibers. However, the individual fibers also act as crack stoppers. Stress transfer from the polymer matrix to the fibers is essential. This is only possible if the fibers have a length equal or greater than the critical fiber length. The critical fiber lengths to diameter ratio of E- glass micro fibers vary between [140 $\mu \mathrm{m}$ length and $6 \mu \mathrm{m}$ in diameter]. Also, the position and orientation of the reinforcement within a structure is known to influence its mechanical properties. ${ }^{(10)}$

The question arises whether this new flowable SFRC material is able to reinforce the dental structure that lead to improve fracture resistance and more favorable fracture patterns when applied according to biomimetic principles. ${ }^{(1)}$ Thus, the sole purpose of the present study was to give clinicians a comparative overview exclusively on the fracture resistance of biomimetic material flowable SFRC and bulk fill flow posterior restorative material. 


\section{MATERIALS AND METHODS}

\section{Teeth selection:}

Following approval of the study protocol by the local ethics committee, 60 intact maxillary premolars extracted for orthodontic reasons were selected. The teeth were selected to be approximately similar in buccolingual (BL) and mesiodistal (MD) dimensions ( $9.2 \pm 0.5$ and $7 \pm 0.5 \mathrm{~mm}$, respectively). Teeth with defects and fracture lines were excluded. After cleaning, the teeth were stored in $0.5 \%$ chloramine solution and then distilled water.

The roots of all the teeth were covered with a thin layer $(0.2-0.3 \mathrm{~mm})$ of wax and embedded in a cylinder of self-curing acrylic resin up to $1 \mathrm{~mm}$ apical to the cemento-enamel junction (CEJ). After resin setting, the teeth were removed from the resin cylinder, and then the covering wax was melted by immersing them in boiling water. This space was filled with polyether impression material, and the teeth were reinserted into the cylinders. The resulting layer mimicked the periodontal ligament. The long axis of the tooth was perpendicular to the base of the cylinder.

\section{Cavities preparation:}

Standardized wide mesio-occluso-distal (MOD) cavities were prepared on 45 randomly selected premolars, with the gingival margin placed $1 \mathrm{~mm}$ coronal to the CEJ, using cylindrical diamond burs. The cavity dimensions were: occlusal width $=1 / 2$ of inter-cuspal width; pulpal depth $=2.5 \mathrm{~mm}$; proximal box width $=1 / 2$ of buccolingual dimensions; and axial depth $=1.5 \mathrm{~mm}$. The facial and palatal walls of the cavities were parallel to the long axis of the teeth. The cavosurface margins were prepared at $90^{\circ}$ with rounded internal line angles.

One experienced operator made all preparations. Measurements were made with a caliper with 0.2$\mathrm{mm}$ sensitivity for proper and accurate standardization of cavity dimensions.

\section{Grouping:}

The randomly non prepared 15 premolars were labeled as Group A, teeth were intact without any cavity to serve as (negative control). After wide MOD cavities were prepared for the 45 premolars, they are randomly divided into 3 groups of 15 each. Group B, the teeth with MOD cavities without any restoration (positive control); Group $\boldsymbol{C}$, the teeth will be restored with bulkfill flowable composite Tetric N flow bulk fill (Ivoclar Vivadent); and group $D$, the teeth will be restored with short fibers reinforced bulkfill flowable composite ever X Flow (GC).

Table (1) The materials used.

\begin{tabular}{|c|l|l|l|l|}
\hline Material & \multicolumn{1}{|c|}{ Type } & \multicolumn{1}{c|}{ Composition } & \multicolumn{1}{c|}{$\begin{array}{c}\text { LOT } \\
\text { number }\end{array}$} \\
\hline everX Flow & $\begin{array}{l}\text { Short fiber reinforced } \\
\text { flowable composite for } \\
\text { dentin replacement (Bulk } \\
\text { shade) }\end{array}$ & $\begin{array}{l}\text { ever X Flow is based on a combination of organic } \\
\text { resin matrix and inorganic glass fibers and filler } \\
\text { particles. The resin matrix contains Bis-MEPP } \\
15-25 \%, \text { TEGDMA 1-10\% and UDMA 1-10\%. } \\
\text { The fillers are a mix of short E-glass fibers and } \\
\text { particle fillers, mostly barium glass Average } \\
\text { length of fibers 140 } \mu \text { m diameter 6 } \mu \text { m. The total } \\
\text { filler rate of ever X Flow is 70\% in weight. \% of } \\
\text { fibers (w/w) 25\% }\end{array}$ & $\begin{array}{l}\text { GC corporation } \\
\text { Tokyo, Japan }\end{array}$ & 1910162 \\
\hline Tetric N-flow & $\begin{array}{l}\text { Bulk fill flowable light } \\
\text { cured composite }\end{array}$ & $\begin{array}{l}\text { Uriethyleneglycol dimethacrylate - 7.3 Barium } \\
\text { glass, ytterbium trifluoride, mixed oxide, silicon } \\
\text { dioxide 63.8\% } \\
\text { Additives, stabilizers, catalysts, pigments 1.1\% }\end{array}$ & $\begin{array}{l}\text { Ivoclar Vivadent AG } \\
\text { Schan Liechtenstein }\end{array}$ & Y39762 \\
\hline
\end{tabular}




\section{Restorative steps:}

Every prepared tooth was subjected to the following; washing with air water spray, Tofflemire matrix application then application of $\mathrm{N}$ etch $37 \%$ phosphoric acid (Ivoclar Vivadent AG Schan Liechtenstein) 30s for enamel and 15s for dentine followed with thorough water washing for $20 \mathrm{~s}$ then gentle air dryness for $5 \mathrm{~s}$ only. application of futurabond $\mathrm{M}+$ universal dental adhesive (VOCO Cuxhaven Germany) for 10 seconds with brush rubbing followed with air thinning for $2 \mathrm{~s}$. adhesive was light cured for $10 \mathrm{~s}$ with light curing unit (LED cordless $10 \mathrm{~W}$ APOZA Enterprise Co., Ltd.Taiwan) at $2000 \mathrm{~mW} / \mathrm{cm} 2$ light intensity

\section{Group C:}

Immediately after curing of dental adhesive, Tetric $\mathrm{N}$ flow bulk fill (Ivoclar Vivadent) was applied into the cavity as one layer to fill both proximal boxes and occlusal cavity leaving only $1 \mathrm{~mm}$ from occlusal cavo-surface angle, then light curing for $10 \mathrm{~s}$ with light curing unit (LED cordless $10 \mathrm{~W}$ APOZA Enterprise Co., Ltd.Taiwan) at $2000 \mathrm{~mW} /$ $\mathrm{cm} 2$ light intensity. Superficial $1 \mathrm{~mm}$ of universal resin composite essential (GC corporation Tokyo, Japan) was applied and cured for 10s with the same light curing unit.

\section{Group D}

everX Flow (GC corporation Tokyo, Japan) was applied into the cavity as one layer to fill both proximal boxes and occlusal cavity leaving only $1 \mathrm{~mm}$ from occlusal cavo-surface angle, then light curing for $10 \mathrm{~s}$ with light curing unit (LED cordless 10 W APOZA Enterprise Co., Ltd.Taiwan) at $2000 \mathrm{~mW} / \mathrm{cm} 2$ light intensity. superficial $1 \mathrm{~mm}$ of universal resin composite essential (GC corporation Tokyo, Japan) was applied and cured for 10s with the same light curing unit.

All materials are applied according to the respective manufacturers' instructions. After finishing the restorations with Sof-Lex discs (3M ESPE), they were stored in distilled water for 24 hours at $37^{\circ} \mathrm{C}$.

\section{Fracture resistance assessment:}

After one day of water storage, the specimens of four groups were subjected to fracture strength measuring; a continuous compressive axial loading at a $1-\mathrm{mm} / \mathrm{min}$ crosshead speed using a universal testing machine (Zwick Roell, Ulm, Germany). The force was applied by a smooth cylindrical head measuring $5 \mathrm{~mm}$ in diameter, parallel to the long axis of the teeth in contact with the occlusal slopes of the buccal and lingual cusps. Peak load to fracture for each tooth was recorded in Newtons as a fracture strength value. Data were analyzed with one-way ANOVA at a significance level of $\alpha=0.05$, using SPSS 11.5 (SPSS Inc., Chicago, IL).

\section{Failure pattern assessment:}

The fractured teeth were then evaluated by two independent operators to determine the mode of fractures, as:

Type I fracture; fracture of enamel only.

Type II fracture; fracture of enamel and dentin with no root involvement.

Type III fracture; fracture of enamel and dentin with root involvement.

Both type I and II considered as restorable fracture because they ending above the CEJ. Type III considered as non-restorable fracture because they ending more than $1 \mathrm{~mm}$ below the CEJ).

\section{RESULTS}

\section{I- Results of fracture resistance assessment:}

The highest mean fracture load value was recorded in group A $1216.6 \pm 352.2$ followed with 1019.7 \pm 164.8 for group D then $1013.3 \pm 389.6$ for group $\mathrm{C}$ while the lowest mean fracture load value $330.6 \pm$ 201.5 was recorded in group B. One-way ANOVA test revealed that the difference between groups was statistically significant $(\mathrm{p}=0.00)$. Tukey' $\mathrm{s}$ post hoc test revealed significant difference between group B with all other groups at the 0.05 level. 


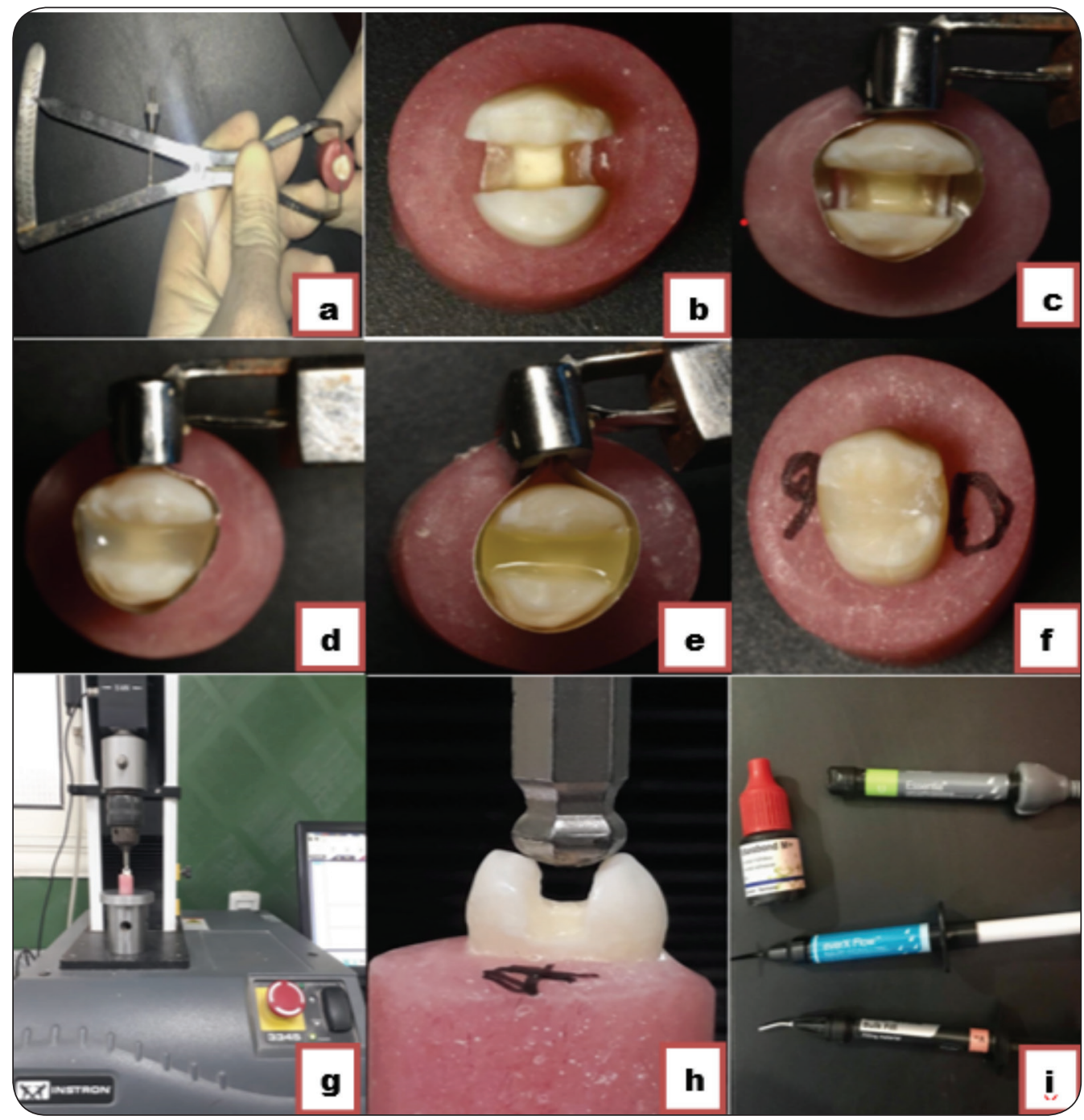

Fig. (1) Steps of samples preparations; $\boldsymbol{a}$-premolars dimensions determination, $\boldsymbol{b}$-wide MOD cavity prepared, $\boldsymbol{c}$-Tofflemire matrix and adhesive applications, $\boldsymbol{d}$-sample with Tetric $\mathrm{N}$ flow composite (group C), $\boldsymbol{e}$-sample with everX flow composite (group D), $\boldsymbol{f}$-superfacial layer of universal composite application, $\boldsymbol{g}$-universal testing machine, $\boldsymbol{h}$-cylindrical head on buccal and palatal slopes of premolar to measure fracture resistance, $i$-different materials used.

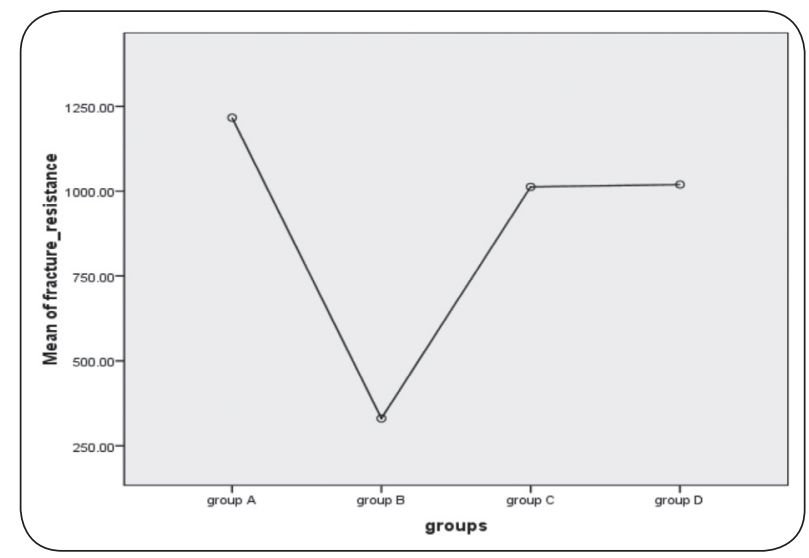

Fig. (2) Fracture resistance results.

\section{II- Results of Failure pattern assessment:}

The negative control (group A) predominantly fractured with restorable patterns $80 \%$ with the highest type I fracture. While the positive control (group B) predominantly fractured in non-restorable patterns $80 \%$ with the highest type III fracture. Fracture pattern for group $\mathrm{C}$ was $80 \%$ restorable fracture and for group D was $66.67 \%$ restorable fracture. 
Table (2) Failure patterns and percentages of restorable and non-restorable failure in each group.

\begin{tabular}{|c|c|c|c|c|c|}
\hline \multirow[t]{2}{*}{ Groups } & \multicolumn{3}{|c|}{ Failure pattern } & \multirow{2}{*}{$\begin{array}{l}\text { Percentage of } \\
\text { restorable fracture }\end{array}$} & \multirow{2}{*}{$\begin{array}{l}\text { Percentage of non- } \\
\text { restorable fracture }\end{array}$} \\
\hline & Enamel fracture & $\begin{array}{c}\text { Enamel and } \\
\text { dentine fracture }\end{array}$ & $\begin{array}{c}\text { Enamel and dentine } \\
\text { fracture with root fracture }\end{array}$ & & \\
\hline Group A & 7 & 5 & 3 & $80 \%$ & $20 \%$ \\
\hline Group B & 0 & 3 & 12 & $20 \%$ & $80 \%$ \\
\hline Group C & 5 & 7 & 3 & $80 \%$ & $20 \%$ \\
\hline Group D & 2 & 8 & 5 & 66.67 & 33.33 \\
\hline
\end{tabular}

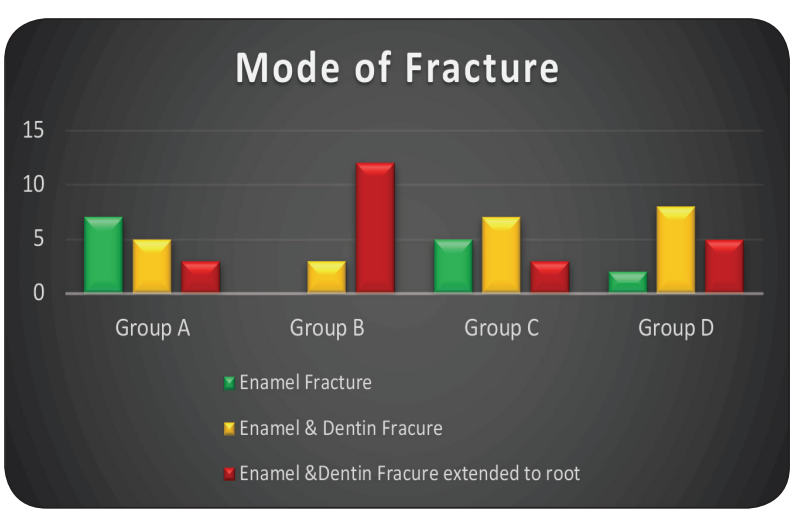

Fig. (3) The results of fracture mode.
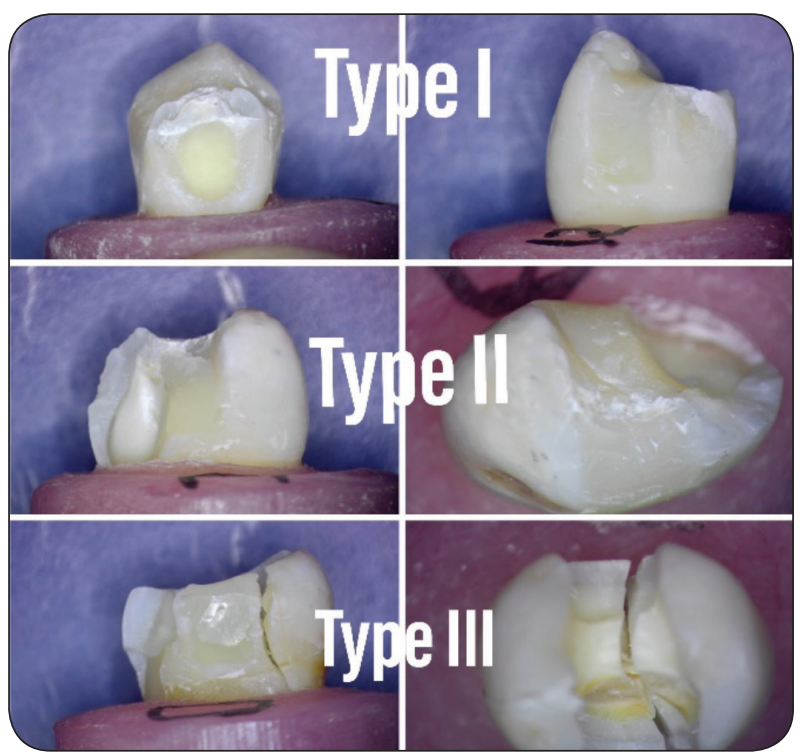

Fig. (4) The different modes of fractures (two examples of every type).

\section{DISCUSSION}

The aims of this study were to evaluate the fracture resistance of premolar teeth by using a standardized MOD preparation restored with SFRC and to compare it with bulk fill flow composite materials. The most critical factor associated with crown fractures is the weakening of tooth structures by caries and large unsupported intra coronal restorations. In this study we tested teeth with large MOD cavities that are more prone to fracture due to construction in the cervical zone and cuspal inclination with high tensions on cusps This is supported by studies demonstrating that any cavity preparation significantly reduces dental fracture resistance. ${ }^{(12,13)}$

Another factor that responsible for weakening the tooth is the polymerization shrinkage of a resin composite that can create contraction forces which may disrupt the bond to cavity walls or cause deformation on the surrounded tooth structure lead to tooth fracture. ${ }^{(14)}$

In the present study we selected the bulk fill flow composite Because the correlation between the polymerization shrinkage and weakening for the restoration, explained with some studies showed that bulk fill flow composites could reduce polymerization shrinkage in posterior teeth. Due to their low elastic modulus which act as a flexible layer and might relieve stresses of the cavity during polymerization. This probably explains why the bulk fill flow composite helped in increase the fracture resistance of teeth with MOD cavity preparations. ${ }^{(15)}$ 
In this study, we used an alternative bi-layered technique or biomimetic composite structure which is a restoration that includes both fibers reinforced composite (FRC) and particulate filler composite (PFC), Due to several studies have shown that the FRC substructure supported the composite restoration and served as a crack-prevention layer. SFRC was introduced as a dentine-replacing material (bulk base) to support the remaining tooth structure and improve the durability of the final biomimetic composite restoration. ${ }^{(16)}$

SFRC materials exhibits uniquefiber and polymer variety in their composition, and consequently, a variety of enhanced mechanical and physical properties. The biomimetic restorative technique, using SFRC as a substructure with conventional composite overlying it, is a recommended direct restoration alternative, and can be used reliably for the coronal restorations of teeth with large cavities in high stress- bearing areas. It also distributes the stressess caused by polymerization shrinkage and load testing more evenly due to the gradient concentration of its nanofillers. ${ }^{(17)}$

According to our results, flowable SFRC has a non significantly higher fracture resistance compared to bulk fill flow composite resin. This might be attributed to lower polymerization shrinkage strain due to fiber content. These fibers could provide an isotropic reinforcing effect because each fiber behaves as a crack stopper and stress transfer from the polymer matrix to stronger fibers. Furthermore, SFRC can absorb stresses and dissipate energy similar to dentin, improving mechanical performance by preventing brittle failure and preserving structural integrity. ${ }^{(5)}$

Confirming the previously mentioned laboratory data, many authors have demonstrated in their clinical reports that using SFRC as a bulk base or core under direct composite restorations for posterior teeth can be considered an economical and practical measure that could obviate the use of extensive prosthetic treatment. ${ }^{(18,19)}$ In contrast to the previously mentioned studies, some investigators reported that the incorporation of SFRC inside the cavity of posterior destroyed teeth restored with thick PFC resin overlays is not useful to increase their fracture resistance. They explained that the discrepancy between their studies and previous studies resulted from a difference in the thickness of overlay PFC composites, loading set-up and the adhesive system used. ${ }^{(20-22)}$

Some authors determined the fracture resistance of SFRC in comparison to different commercial composite resins, and stated that SFRC differed significantly in its physical properties and has superior fracture resistance compared to other tested bulk- fill or conventional composite materials (23), with the difference that in our study we used both tested materials in a flowable bulk fill form .

The failure patterns observed in the current study showed $66.7 \%$ restorable fracture in SFRC group that is significantly higher than cavitated non filled group as SFRC is able to sustain compressive static load.This results were in accordance with authors that evaluated the mechanical properties of SFRC in comparison to other composite resin materials and declared that the toughening capability of SFRC over their competition is attributed to two main factors: the millimeter-scale short fiber and semi-inter penetrating network (IPN) structure. Therefore, they recommended SFRC in high stressbearing areas for its enhanced toughness. ${ }^{24,25)}$

Restorable fracture was $80 \%$ for teeth restored with bulk fill flowable composite that is comparable to negative control group (sound non cavitated teeth),this is attributed to the evolution that made the bulk fill flow composites more flexural strength, more flow and less shrinkage with less cuspal strains as stated by authors about bulk fill flow composite $^{(26,27)}$

The increase in non restorable fracture in teeth restored with SFRC(everX flow) compared to teeth filled with bulk fill flow(Tetric $\mathrm{N}$ flow) restorations could be due to the thicker consistency of SFRC due to the added short fibers, impairing bonding resistance and favoring breakdown of the adhesive interface. ${ }^{(12)}$ 


\section{CONCLUSION}

Within the limitations of this study, it was possible to conclude that both bulk fill flowable composite and short fiber reinforced flowable composite can increase the fracture resistance of extensively prepared mesio-occluso-distal cavities of maxillary premolars to the limit near the sound non prepared premolars, with no significant difference between the two tested materials.

\section{REFERENCES}

1. Dalpino PH, Francischone CE and Ishikiriama A. Fracture resistance of teeth directly and indirectly restored with composite resin and indirectly restored with ceramic materials. Am J Dent. 2002; 15:389-394.

2. Ferracane JL. Resin composite - state of art. Dent Mater. 2011; 27:29-38

3. Kuijs RH, Fennis WM, Kreulen CM, Barink M and Verdonschot N. Does layering minimize shrinkage stresses in composite restorations?. J Dent Res. 2003;82:967-971.

4. Vallittu PK. High- aspect ratio fillers: Fiber- reinforced composites and their anisotropic properties. Dent Mater. 2015;31:1-7.

5. Garoushi S, Gargoum A, Vallittu PK and Lassila L. Short fiber- reinforced composite restorations: A review of the current literature. J Invest Clin Dent. 2018; 9:123-130.

6. Keulemans F, Garoushi S, Lassila L, Vallittu P and Özcan M. Fillings and core build-ups: A Clinical Guide to Principles of Fibre Reinforced Composites (FRCs) in Dentistry. Duxford: Woodhead Publishing. 2017:131-163.

7. Abouelleil H, Pradelle N, Villat C, Attik N, Colon P and Grosgogeat B. Comparison of mechanical properties of a new fiber reinforced composite and bulk filling composites. Restor Dent Endod. 2015; 40:262-270.

8. Bijelic-Donova J, Garoushi S, Lassila LV, Keulemans F and Vallittu PK. Mechanical and structural characterization of discontinuous fiber-reinforced dental resin composite. J Dent. 2016; 52:70-78.

9. Huang Q, Qin W and Garoushi S. Physicochemical properties of discontinuous glass fiber reinforced resin composite. Dent Mater J. 2018; 37:95-103.

10. Heintze SD, Ilie N, Hickel R, Reis A, Loguercio A and Rousson V. Laboratory mechanical parameters of composite resins and their relation to fractures and wear in clinical trials- A systematic review. Dent Mater. 2017; 33:101-114.

11. Tsujimoto A, Barkmeier WW and Takamizawa T. Relationship between mechanical properties and bond durability of short fiber- reinforced resin composite with universal adhesive. Eur J Oral Sci. 2016; 124:480-489.

12. Camacho GB, Goncalves M and Nonaka T. Fracture strength of restored premolars. Am J Dent. 2007; 20:121-124.

13. de Freitas CR, Miranda MI, de Andrade MF. Resistance to maxillary premolar fractures after restoration of class II preparations with resin composite or ceromer. Quintessence Int. 2002; 33:589-594.

14. Tezvergil A, Lassila LV and Vallittu PK. The effect of fiber orientation on the polymerization shrinkage strain of fiberreinforced composites. Dent Mater. 2006; 22:610-616.

15. Golsa DDS, Hamideh MS and Chasteen DDS. Fracture resistance of premolar teeth restored with silorane-based or dimethacrylate-based composite resins. J Esth \& Rest Dent. 2014;26: 200-207.

16. Eapen AM, Amirtharaj LV, Sanjeev K and Mahalaxmi S. Fracture resistance of endodontically treated teeth restored with 2 different fiber- reinforced composite and 2 conventional composite resin core buildup materials: An in vitro study. J Endod. 2017; 43:1499-1504.

17. Tsujimoto A, Barkmeier WW and Takamizawa T. Relationship between mechanical properties and bond durability of short fiber- reinforced resin composite with universal adhesive. Eur J Oral Sci. 2016; 124:480-489.

18. Soares R, Ataide N, Fernandes M and Lambor R. Fiber reinforcement in a structurally compromised endodontically treated molar: A case report. Rest Dent \& Endod. 2016; 41:152-154.

19. Garoushi S, Tanner J, Vallittu P and Lassila L. Preliminary clinical evaluation of short fiber- reinforced composite resin in posterior teeth: 12- months report. Open Dent J. $2012 ; 6: 41-45$.

20. Atalay C, Yazici AR, Horuztep A, Nagas E, Ertan A and Ozgunaltay G. Fracture resistance of endodontically treated teeth restored with bulk fill, bulk fill flowable, fiber- reinforced, and conventional composite. Oper Dent J. 2016; 41:131-140.

21. Rocca GT, Saratti CM, Cattani-Lorente M, Feilzer AJ, Scherrer S and Krejci I. The effect of a fiber reinforced cavity configuration on load bearing capacity and failure 
mode of endodontically treated molars restored with CAD/ CAM resin composite overlay restorations. J Dent. 2015; 43:1106-1115.

22. Barreto BC, Van Ende A and Lise DP. Short fibre- reinforced composite for extensive direct restorations: A laboratory and computational assessment. Clin Oral Investig. 2016; 20:959-966.

23. Garoushi S, Säilynoja E, Vallittu PK and Lassila L. Physical properties and depth of cure of a new short fiber reinforced composite. Dent Mater. 2013; 29:835-841.

24. Bijelic-Donova J, Garoushi S, Lassila LV, Keulemans F, Vallittu PK. Mechanical and structural characterization of discontinuous fiber- reinforced dental resin composite. J
Dent. 2016; 52:70-78.

25. Bijelic-Donova J, Garoushi S, Vallittu PK, Lassila LV. Mechanical properties, fracture resistance, and fatigue limits of short fiber reinforced dental composite resin. J Prosthet Dent. 2016; 115:95-102.

26. Eweis AH, Yap AU and Yahya NA. Comparison of Flexural Properties of Bulk-fill Restorative/Flowable Composites and Their Conventional Counterparts. Oper Dent. 2020; 45:41-51.

27. Tobias T, Franziska $J$ and Thomas A. Polymerization shrinkage and shrinkage force kinetics of high- and lowviscosity dimethacrylate- and ormocer-based bulk-fill resin composites. Odont J. 2019;107:103-110. 
مجلة أسيوط لطب الأسنان

النشر الرسمي لكلية طب الأسنان

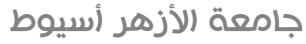

\section{كفاءة مركب الحشو الكتلم القابل للتدفق والمقوص بالألياف القصيرة فن مقاومة الكسر للأسنان الضواحك ذات التجاويف الواسعة}

أحمد علي جودة 1 ، أحمد ضاحي أبوجبل 2

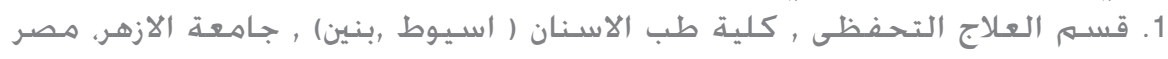

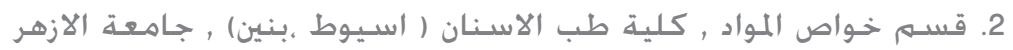

البريد الالكترونى للباحث الرئيسى: AHMEDALI@AZHAR.EDU.EG *

(الملخص : (1) n

الهـدف: سـعت هذه الدراسـة إلي تقييم تأثير الحشـو الكتلي القابل للتدفق والمقوي بالألياف القصيرة علي مقاومة الكسـر للأسـنان الضواحك ذات التجاويف الواسعـة.

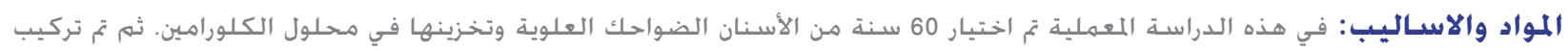

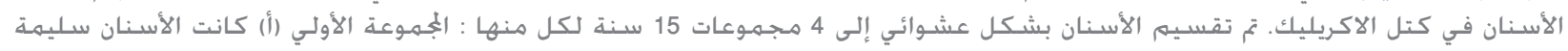

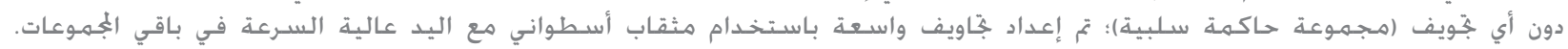

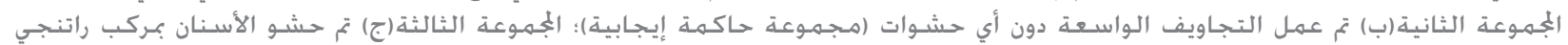

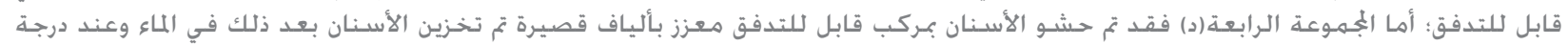

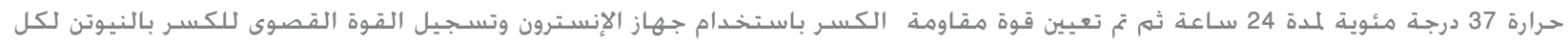

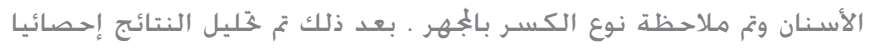

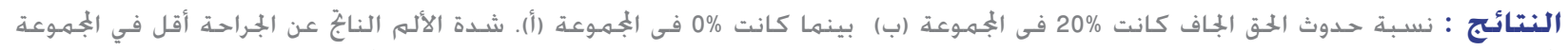

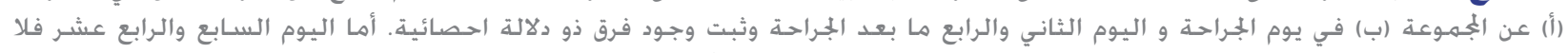

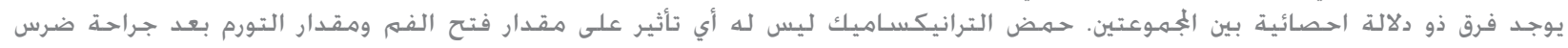
العقل السـفلى.

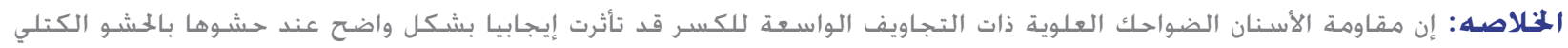

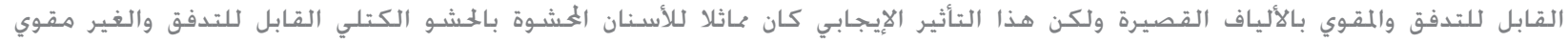
بالألياف القصيرة الكعلمات المفتاحية: الحشـو الكتلي القابل للتدفق ، الألياف القصيرة ، مقاومة الكسـر ، الضواحك ذات التجاويف الواسعة , قوى الضغط. 